\title{
Microstructure and mechanical properties affecting crack growth behaviour in AA6060 produced by equal-channel angular extrusion
}

\author{
L.W. Meyer ${ }^{a}$, K. Sommer ${ }^{b}$, T. Halle $^{c}$, M. Hockauf ${ }^{d}$ \\ Chemnitz University of Technology, Institute of Materials and Impact Engineering, Erfenschlager \\ Str. 73, 09125 Chemnitz, Germany \\ alothar.meyer@wsk.tu-chemnitz.de, 'bristin.sommer@mb.tu-chemnitz.de (corresponding author), \\ 'thal@hrz.tu-chemnitz.de, ${ }^{d}$ matthias.hockauf@mb.tu-chemnitz.de
}

Keywords: aluminium alloy, ECAP, fatigue crack growth, ultrafine grain, bimodal, heat treatment, ductility

\begin{abstract}
Crack growth in AA6060 after two and eight equal-channel angular extrusions (ECAE), showing a bimodal microstructure and a homogenous ultrafine-grained microstructure, respectively, are compared to the coarse grained counterpart. Furthermore, an optimized condition, obtained by combining one ECA-extrusion and a subsequent short aging treatment is included. Fatigue crack growth behaviour in the near-threshold regime and the region of stable crack growth is investigated and related to microstructural features such as grain size, grain size distribution, grain boundary characteristics and ductility. Micrographs of crack propagation surfaces reveal information on crack propagation features such as crack path deflection and give an insight to the underlying microstructure. Instrumented Charpy impact tests are performed to investigate crack initiation and propagation under impact conditions. Due to the recovery of ductility during the post-ECAE heat treatment, the optimized condition shows improved fatigue crack properties and higher energy consumption in Charpy impact tests, when compared to the as-processed conditions without heat treatment.
\end{abstract}

\section{Introduction}

In the last decade equal channel angular pressing /extrusion (ECAP/E) as a method of severe plastic deformation (SPD) has become a widely applied method for enhancing the strength of a bulk metallic material by producing an ultrafine-grained (UFG) microstructure [1,2]. Besides the favourable strength enhancement, which also exerts a positive effect on the material's high cycle fatigue life, a drawback of the as-processed materials is seen in their significantly reduced ductility, which primarily results from the high amount of strain hardening which is introduced during ECAP $[3,4]$. Hence, such materials usually show a significant decrease in low cycle fatigue (LCF) life. In conjunction with fatigue life experiments, characterisation of crack initiation and growth in UFG materials have become a subject of increased interest. Vinogradov et al. [5,6] have clearly shown, that an ECAP-processed UFG material generally exhibits the same stages of crack propagation as a conventional coarse grained (CG) material: (I) a near-threshold region of slow crack advance at a low stress intensity factor range $\Delta \mathrm{K}$, (II) an intermediate stage which can be described by the well known Paris-Erdogan-equation

$$
d a / d N=C(\Delta K)^{m}
$$

and (III) the stage of unstable crack growth at high $\Delta \mathrm{K}$. Compared to their CG counterparts, the UFG microstructures showed a lower fatigue threshold $\Delta \mathrm{K}_{\text {th }}$ and higher crack growth rates da/dN, especially in the near-threshold region. This behaviour has been attributed to a less tortuous crack path and in conjunction with this, to a less intensive roughness-induced crack closure [7]. Besides the reduced grain size of the SPD materials, also the reduced ductility, caused by the diminished strain hardening capability, is supposed to have a derogating influence on crack growth properties. Similar to characteristics of LCF loading, also fatigue crack growth is associated with relatively large cyclic strains and plastic deformation, which occur in the vicinity of the crack tip [6]. As the unfavourable LCF and crack growth properties of the as-processed materials cause a strong 
limitation on the potential fields of practical application, several investigations have been conducted to develop optimized conditions in order to enhance the material's ductility. For precipitation hardening aluminium alloys, the combination of SPD in the solid-solutionized condition with a subsequent aging was found to be a promising method for increasing the materials strength while preserving a good ductility [8,9]. In the present study, a homogeneous and a bimodal UFG condition, as well as an optimized condition, achieved by a combination of ECAE and subsequent short-time aging are compared to the CG counterpart. This enables to characterize and separate the influence of grain size and grain size distribution as well as the influence of ductility on the fatigue crack growth behaviour.

\section{Methods}

For this study commercially extruded $6060 \mathrm{Al}$ alloy in the peak aged condition T6 was used. Repetitive ECA-extrusions were conducted at room temperature (RT) in a die with two square channels intersecting in a $90^{\circ}$ angle. For the as-processed conditions, the billets were extruded from the T6 condition for two and for eight passes, respectively. For obtaining the optimized condition, first, the material was solid-solution heat treated at $525^{\circ} \mathrm{C}$ for an hour, quenched to RT and then extruded at RT for one pass. Subsequently, a short aging for 18 minutes was conducted at $170{ }^{\circ} \mathrm{C}$. Those parameters were chosen referring to an extended investigation on the post-ECAE precipitation kinetics of this material, where this particular aging time led to a post-ECAE peak age condition [8]. Tensile tests were conducted at an initial strain rate of $10^{-3} \mathrm{~s}^{-1}$, using round specimens with a diameter of $3.5 \mathrm{~mm}$ and a gauge length of $10.5 \mathrm{~mm}$. For fatigue crack growth measurements, single edge bend (SEB) specimens with a geometry according to ASTM E399 and a thickness of $6.5 \mathrm{~mm}$ were used. Crack growth experiments have been carried out $\Delta \mathrm{K}$-controlled in a "RUMUL" resonant testing machine, applying a constant load ratio of $\mathrm{R}=\mathrm{K}_{\min } / \mathrm{K}_{\max }=0.1$. With miniature Charpy ISO V-notch specimens with a cross section of $4 \times 4 \mathrm{~mm}^{2}$ and a notch depth of $1 \mathrm{~mm}$, instrumented Charpy impact tests have been conducted at RT in a miniature 15J impact testing machine. For both, the crack growth and the Charpy impact tests, specimens were extracted from the ECAE-billet as shown in Figure 1. Microstructural investigations were performed by electron backscatter diffraction (EBSD) on disks taken from the flow plane, parallel to the direction of extrusion. For documentation of the crack growth surfaces, micrographs were taken in a SEM “LEO 1455VP”.

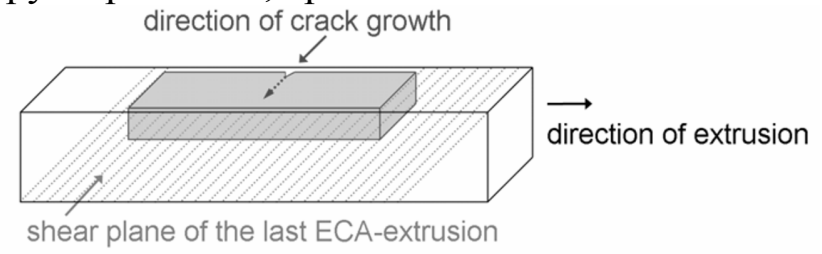

Fig. 1: Position of SEB specimen within ECAE-billet.

\section{Microstructure}

For the material under investigation, detailed studies on the microstructural development with successive ECAE-processing have been conducted previously [10]. Furthermore, in a study regarding combination of ECAE and a subsequent heat treatment, the microstructural features of the
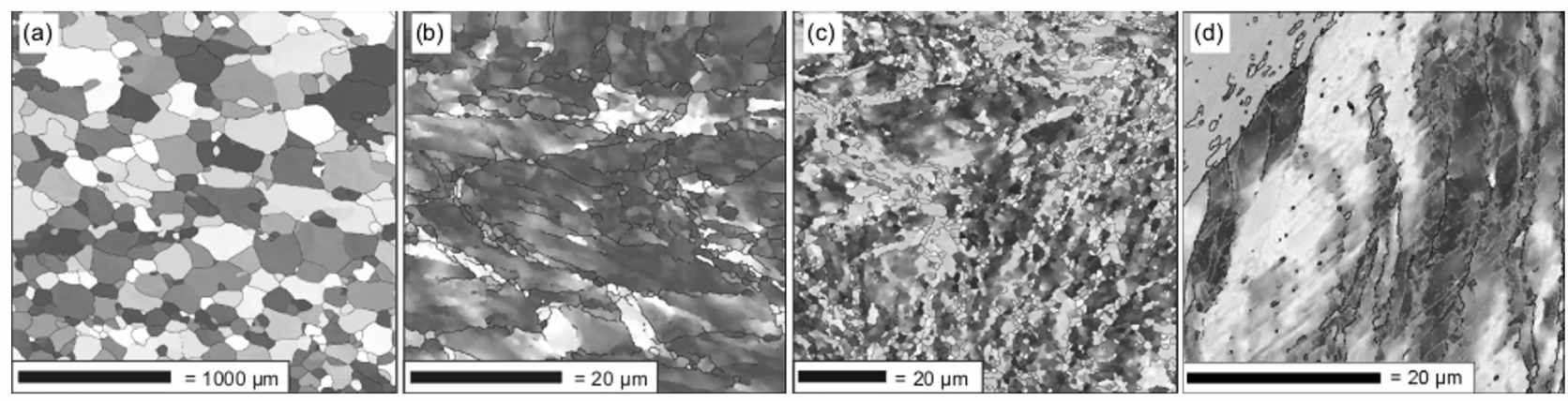

Fig. 2: Orientation maps of the material (a) in the initial CG condition (b) after 2 ECA-extrusions (c) after 8 ECA-extrusions and (d) in the optimized condition (1 ECAE + aging). 
optimized condition presented in this study, have been investigated thoroughly [8]. Within this section, only a brief discussion on the relevant features will be presented. Figure 2 shows EBSD maps of the conditions under investigation. High angle grain boundaries (HABs) with a misorientation angle $\geq 15^{\circ}$ are marked as black lines. The initial material consists of coarse globular grains with an average size of about $100 \mu \mathrm{m}$. In the material after two extrusions, those grains are elongated in the directions of macroscopic shear during ECAE. Furthermore micro shear bands are present in this microstructure, separated from the surrounding matrix by a high misorientation angle. Within those bands, numerous very small equiaxed sub-grains have formed, causing a bimodal appearance. After eight extrusions, the material is completely pervaded by micro shear bands. In this state, the microstructure can be considered as homogeneously refined, consisting fully of ultrafine grains in the range of $1 \mu \mathrm{m}$ and smaller. As described in [10], LABs which are introduced during the first passes, are successively converted into HABs during further ECA-extrusions. For the optimized condition, ECAE-processing from the solid-solutionized state, followed by a subsequent short aging, leads to a large amount of LABs. These are generated due to the formation of subgrains during SPD on the one hand and in a recovery process during subsequent aging on the other hand [8]. In contrast to the as-processed condition after two extrusions, the microstructure gets refined nearly homogeneously. Nevertheless, a certain pattern can be found within the microstructure, as HABs are oriented as parallel walls with numerous sub-grains in between, which are separated by LABs. During post-ECAE aging, high internal stresses are recovered, resulting in a higher strain hardening capability and an increase in ductility. Further, the subsequent heat treatment leads to the formation of very fine precipitations, preferably located in the area of remaining dislocations, which cause an additional increase in strength [10,11].

\section{Tensile behaviour}

From the tensile stress-strain curves in Figure 3 it can be seen that the ductility has decreased significantly for the as-processed conditions, compared to the initial CG condition. With a uniform elongation (UE) of only about 1\%, those materials' strain hardening capability has been almost exhausted during SPD processing. By contrast, the optimized condition after one extrusion and subsequent aging shows an UE of $7 \%$ which is only slightly below the CG initial condition. Nevertheless, the optimized condition shows an increase in yield strength of about $39 \%$ when compared to the CG counterpart. Also the ratio of yield stress to tensile strength reveals that for the optimized condition a certain capability for strain hardening has been regained during aging. For the investigated conditions, strength and ductility properties from tensile tests as well as the coefficients of the Paris-Erdogan-relation, describing crack growth in stage II, are given in Table 1.

Tab. 1 Tensile properties, coefficients for Paris-Erdogan (Eq. 1) and fatigue crack threshold, R=0.1.

\begin{tabular}{lccccccc}
\hline \hline \multicolumn{1}{c}{ Condition } & $\begin{array}{c}\text { YS } \\
{[\mathrm{MPa}]}\end{array}$ & $\begin{array}{c}\text { UTS } \\
{[\mathrm{MPa}]}\end{array}$ & $\begin{array}{c}\text { UE } \\
{[\%]}\end{array}$ & $\begin{array}{c}\text { Elong. to } \\
\text { failure [\%] }\end{array}$ & $\begin{array}{c}\mathrm{C} \\
{[\mathrm{m} / \mathrm{cycle}]}\end{array}$ & $\mathrm{m}$ & $\begin{array}{c}\Delta \mathrm{K}_{\text {th }} \\
{\left[\mathrm{MPam}^{1 / 2}\right]}\end{array}$ \\
\hline CG initial (T6) & 208 & 233 & 9.1 & 25.6 & $2.664 \cdot 10^{-12}$ & 4.394 & 3.2 \\
2 ECA-extrusions & 316 & 322 & 1 & 17.4 & $5.787 \cdot 10^{-11}$ & 3.128 & 2.1 \\
8 ECA-extrusions & 358 & 368 & 1 & 20.3 & $1.028 \cdot 10^{-10}$ & 3.018 & 1.5 \\
1 ECAE + aging & 290 & 317 & 7.4 & 22.7 & $1.234 \cdot 10^{-11}$ & 4.066 & 2.5 \\
\hline \hline
\end{tabular}

\section{Crack growth behaviour}

Fatigue crack growth behaviour of the conditions under investigation is presented in Figure 4. Scanning electron microscopy (SEM) micrographs of the crack propagation surfaces in Figure 5 give an insight into crack propagation features and the underlying microstructure. To ensure comparability, all micrographs show surfaces of crack propagation at the same cyclic stress intensity of $7 \mathrm{MPam}^{1 / 2}$. As discussed before, fatigue crack propagation is strongly influenced by grain size. This can be seen clearly in the crack growth curves, since the CG condition shows the highest $\Delta \mathrm{K}_{\text {th }}$ and lowest crack propagation rates. Also in Figure 5, a rough and fissured crack propagation surface 


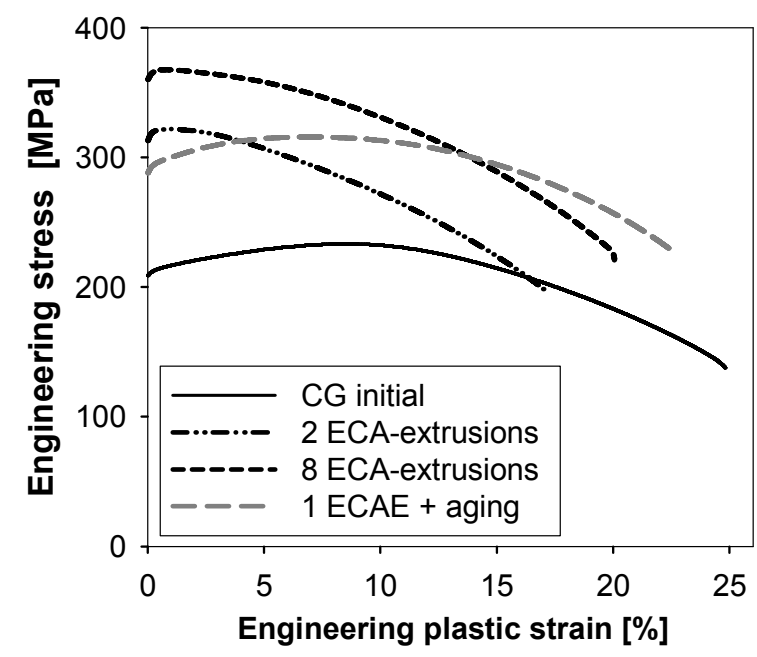

Fig. 3: Engineering stress-strain curves from tensile test.

of the CG conditions reveals a strong crack path deflection, associated with a high amount of energy consumption for crack propagation. Within the two asprocessed conditions, clear differences can be observed, especially in the near-threshold region. Presumably due to its remaining fraction of coarse grains, the bimodal condition shows a higher fatigue threshold and lower crack propagation rates than the homogeneous UFG condition. Also when regarding the crack propagation surfaces, the bimodal condition shows an intermediate behaviour, as it represents a mixture of both, the smooth appearance of the homogeneous UFG condition and rough areas, similar to those in the CG condition. These findings point out clearly the dependence of crack growth properties on grain size and grain size distribution. When analysing SPD materials concerning grain size, also grain boundary characteristics, such as misorientation angles between adjacent grains have to be considered, since the size of (sub-)grains formed by LABs might be significantly smaller

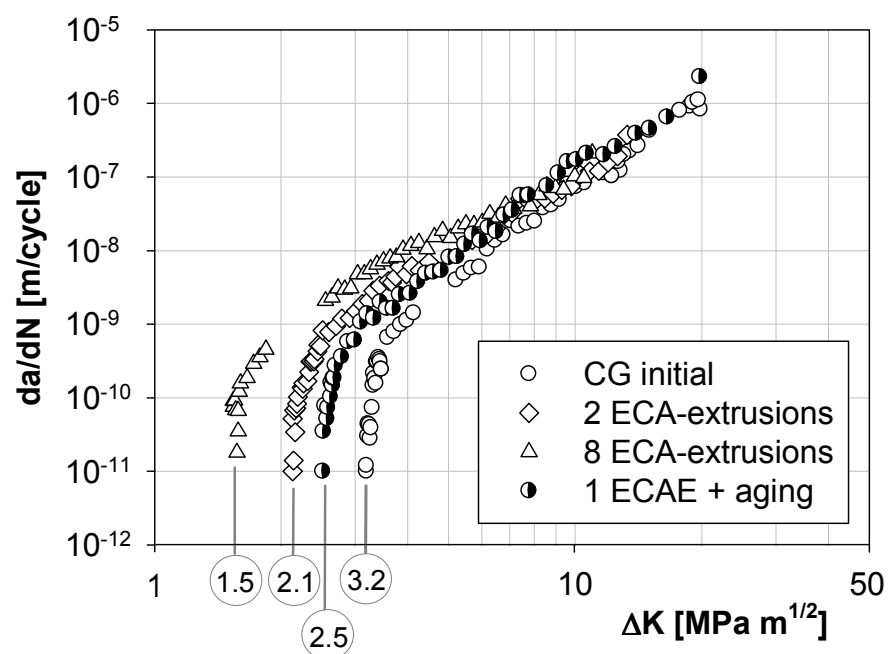

Fig. 4: Fatigue crack growth behaviour at $\mathrm{R}=0.1$.
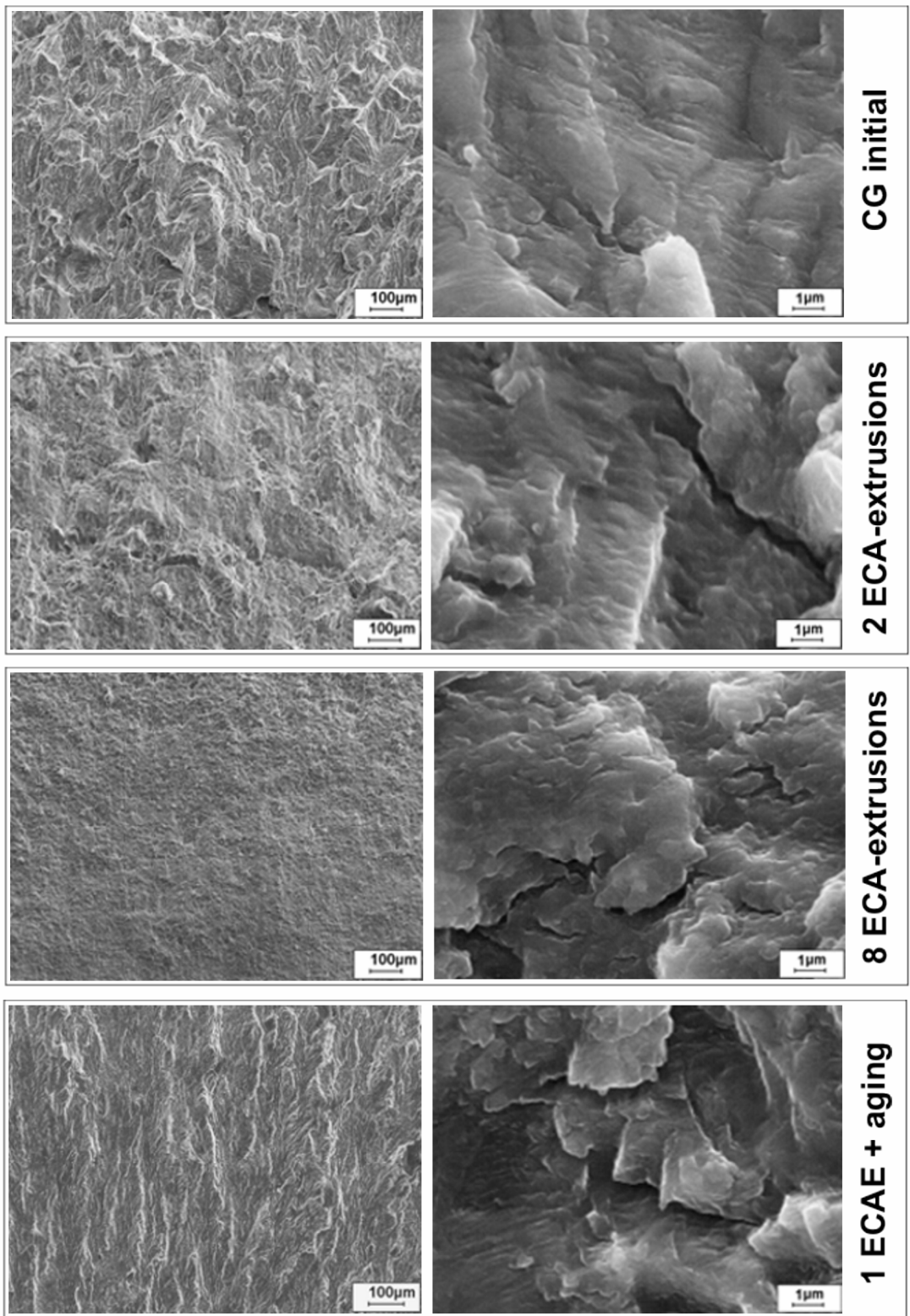

Fig. 5: SEM images of crack propagation surfaces at $\Delta \mathrm{K} \sim 7 \mathrm{MPa} \mathrm{m}^{1 / 2}$, direction of crack growth: $\uparrow$ 
than the size of grains bordered by HABs, as for instance in the optimized condition. As shown in [12], fatigue cracks initiate and propagate preferably along HABs, since they comprise a weaker cohesion in their lattice structure. For crack propagation along a LAB, significantly more energy would be consumed. Within the ECAE-processed conditions, the optimized condition shows the highest fatigue threshold and lowest crack propagation rates. Especially when comparing the optimized with the bimodal condition, a discussion merely based on grain size seems not to be sufficient for explaining the better fatigue properties of the optimized condition. Apparently also the materials ductility, in conjunction with its capability for strain hardening, exerts an influence. As discussed in [6], during fatigue crack growth, fatigue mechanisms are triggered in the plastic zone around the crack tip, similar to those operating at LCF. Limited to slip bands emanating from the crack tip, dislocation movements take place and dislocations are impeded and piled up at obstacles such as (high angle) grain boundaries. Consequently this means, that if the capability for strain hardening in these particular regions is exceeded, microcracks will be initiated, which will ease further crack propagation. For the as-processed materials the decrease in work hardening capability can clearly bee seen in the stress-strain curves from the tensile test. Higher magnified images of the crack propagation surfaces in Figure 5 reveal information on the materials' ductility as well. Brittle crack growth behaviour can be characterised by the amount and length of secondary cracks on the fatigued surface. In contrast, a rather ductile behaviour is revealed by striations, which indicate a pronounced blunting of the crack tip [13]. On the crack surface of the CG condition, perpendicular to the direction of crack growth, such striations can be detected. For the bimodal condition, striations are visible, too, though less pronounced. Additionally on this surface, characteristic secondary cracks can be found, emanating from valleys of the saw-tooth-like striations. For the homogeneous UFG material, numerous dendritic microcracks, presumably initiated along HABs, reveal a rather brittle manner of crack growth. The optimized condition exhibits several nearly parallel edges where the crack has propagated along a HAB. In the interior regions, striations and only a few microcracks are visible, which can be attributed to a rather ductile manner of crack growth.

\section{Charpy impact tests}

To characterize the material's fracture properties under impact conditions, instrumented Charpy impact tests have been performed, Figure 6. The maximum forces in the force-displacement graphs reveal a good conformity with the tensile strength of the respective conditions. The bimodal condition achieves approximately the same impact energy consumption as the CG condition. Though for the bimodal condition the maximum force is higher, the overall consumed energy is limited by the steeper decline of the curve. Attributed to the highest maximum force, the homogeneous UFG condition achieves higher energy consumption than the CG material. Nevertheless it exhibits a steeper decline after the maximum point, indicating that only little energy is consumed during crack propagation. The highest impact energy is achieved by the optimized condition. Similar to the CG condition the relatively gentle decline reveals high energy consumption for crack propagation. According to [14], one can correlate the Charpy impact toughness with the fracture toughness $\mathrm{K}_{\mathrm{C}}$ of a material. For the optimized condition this implies, that its fracture toughness would be higher than for the initial condition. Thus, one could expect the transition to unstable crack growth (stage III) in the crack propagation diagram at higher $\Delta K$.

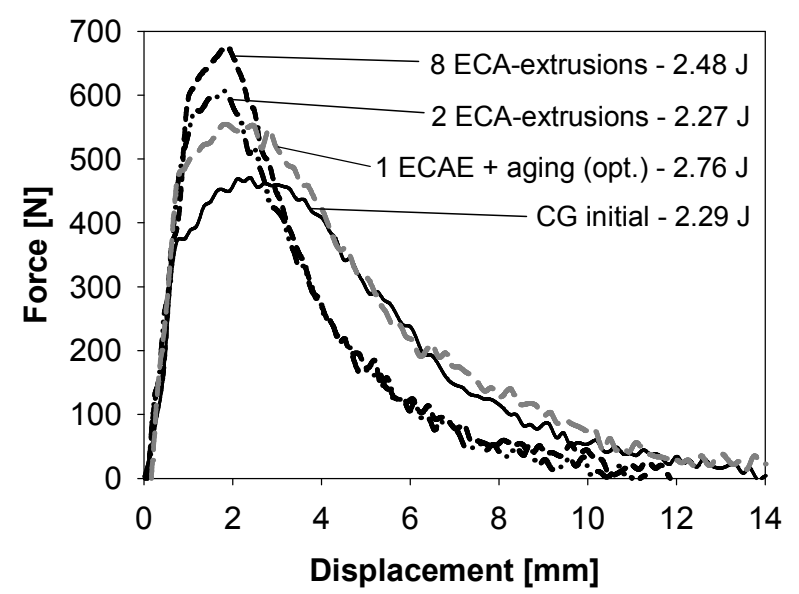

Fig. 6: Load-displacement curves from instrumented Charpy impact tests. 


\section{Conclusions}

Crack growth behaviour of AA6060 in the initial CG condition, a bimodal condition after two ECAextrusions, a homogeneous UFG condition after eight ECA-extrusions and an optimized condition achieved by one ECA-extrusion and subsequent aging was investigated and related to microstructural and mechanical features. For comparing the as-processed conditions, differences in fatigue crack growth behaviour could be attributed to different grain sizes and grain size distributions. The optimized condition shows the best fatigue properties within the SPD conditions, but reveals an apparently smoother crack propagation surface, when compared to the bimodal condition. This implies that the improved ductility and strain hardening capability of the optimized condition also had a positive effect on its crack propagation properties. In miniature Charpy impact tests the optimized condition achieved the highest impact energy, which was also attributed to its favourable combination of increased strength and good ductility.

\section{Acknowledgements}

The authors want to thank the „Deutsche Forschungsgemeinschaft“ for supporting this research within the framework of ,Sonderforschungsbereich 692“.

\section{References}

[1] R.Z. Valiev, R.K. Islamgaliev, I.V. Alexandrov: Prog. Mater. Sci. 45 (2000) 103-189.

[2] Z. Horita, T. Fujinami, M. Nemoto, T.G. Langdon: J. Mater. Process. Technol. 117 (2001) 288292.

[3] HW. Höppel, C. Xu, M. Kautz, N. Barta-Schreiber, T.G. Langdon, H. Mughrabi In: Proc. of Int. Conf. „Nanomaterials by Severe plastic deformation-NANOSPD“, (2004) Wiley-VCH, Weinheim

[4] H. Mughrabi, H.W. Höppel, M. Kautz: Scr. Mater. 51 (2004) 807-812

[5] A.Vinogradov, S. Nagasaki, V. Patlan, K. Kitagawa, N. Kawazoe: Nanostruct. Mater. 11 (1999) 925-934

[6] A. Vinogradov: J. Mater. Sci. 42 (2007) 1797-1808

[7] C.S. Chung, J.K. Kim, H.K. Kim, W.J. Kim: Mater. Sci. Eng. A 337 (2002) 39-44

[8] M. Hockauf, L.W. Meyer, B. Zillmann, M. Hietschold, S. Schulze, L. Krüger: Mater. Sci. Eng. A, corrected proof (in press)

[9] J.K. Kim, H.K. Kim, J.W. Park, W.J. Kim: Scr. Mater. 53 (2005) 1207-1211

[10] M. Hockauf, L.W. Meyer, T. Halle, C. Kuprin, M. Hietschold, S. Schulze, L. Krüger:Int. J. Mat. Res.97 (2006)1392-1400

[11] H.J. Roven, M.Liu, J.C. Werenskiold: Mater. Sci.Eng. A (2007), in press

[12 ] Z.F. Zhang, Z.G. Wang: Mater. Sci. Eng. A 284 (2000) 285-291

[13] S.P. Lynch: Mater. Sci. Eng. A 468-470 (2007) 74-80

[14] L.C.A Folch, F.M. Burdekin: Eng. Fract. Mech. 63 (1999) 57-80 